\title{
Effect of varicocelectomy on sperm parameters, oxidative stress and Chromatin maturity in seminal fluid of infertile patients with varicocele
}

\author{
Ali Jehad N. Al-Huwaizi* \\ Sahib Y. Al-Murshedi** \\ Faris Naji A. Al-Hady* \\ * Faculty of Science, Babylon University. \\ ** Faculty of Medicine, Kufa University. \\ E-mail: ali_jehad20002000@yahoo.com
}

Received 24/6/ 2015

Accepted 9/7/ 2015

(c) $(1) \Theta \Theta$

NoDerivatives 4.0 International Licens
No

\begin{abstract}
:
This study aimed to determine the effect of varicocelectomy on sperm parameters, oxidant- antioxidant status and chromatin maturity percent. The current study has been conducted on 154 infertile patients complaining from varicocele and varicocelomized men in addition to 25 fertile men as control. The results revealed significant decrease $(\mathrm{P}<0.05)$ in sperm concentration, progressive motile sperm percent, normal sperm morphology percent, GSH, SOD1, CAT levels and chromatin maturity percent and significant increase $(\mathrm{P}<0.05)$ in MDA and ROS concentrations in infertile patients with varicocele when compared to fertile men. The results revealed improvement $(\mathrm{P}<0.05)$ of sperm parameters quality, GSH, SOD1, CAT, MDA, ROS concentration and chromatin maturity percent in varicoceloctomized men compared with infertile men with varicocele. It is concluded that varicocelectomy could lead to an improvement of sperm parameters, the oxidant-antioxidant status and chromatin maturity percent but does not reach to the same levels in control group.
\end{abstract}

Key words: Varicocelectomy, Oxidative Stress, Chromatin Maturity

\section{Introduction:}

Varicocele is the most important factor that cause male infertility that are found in about $15 \%$ of general male population and $19 \%$ to $41 \%$ of the infertile male [1]. The etiology of varicocele is not known, but absence of valves within the spermatic veins or present a defect on the valves are considered to participate to occurrence of varococele [2] in addition the increase in venous pressure in the left renal vein and collateral venous anastomosis [3].

Varicocelectomy operation can decrease elevated sperm DNA fragmentation statement, then increase sperm parameters quality, generally should improve pregnancy outcomes [4]. Previous researches have explained the 
effects of increased oxidative stress (OS) in the serum, seminal plasma, and testicular tissues of male with varicocele $[5,6]$. Elevation of seminal OS levels have been correlated with sperm dysfunction through various mechanisms like impairment of sperm motility and lipid peroxidation of the sperm plasma membrane and fertilizing capacity [7] also varicocele can lead to leydig cell dysfunction [8]. This study aimed to determine the effect of varicocelectomy on sperm parameters and the levels of Malondialdehyde (MDA), Reactive oxygen species (ROS), Glutathione (GSH), and superoxide dismutase1 (SOD1), Catalase (CAT) and chromatin maturity percent in seminal fluid of infertile patients with varicocele.

\section{Materials and Methods:}

The current study has been conducted on 154 infertile patients complaining from varicocele $(\mathrm{n}=78)$ and varicocelomized men $(n=76)$ [the mean of postoperative period $( \pm \mathrm{SD}$ ) was 8.48 \pm 4.27 months with range 3-19 months] in addition to 25 fertile men as control who attended to Fertility Center in AlSadr Medical City in An-Najaf Health Directorate/Iraq between January 2014 and February 2015. The clinical assessment was evaluated by urologist for detecting varicocele, hydrocele, cryptorchidism, hernia and other congenital abnormalities in addition to using testicular ultrasound (sonogram). The seminal fluid samples after 3-5 days of abstinence were collected directly in a dry, clean and sterile disposable container by masturbation in a private room, then seminal fluid were placed in incubator at $37^{\circ} \mathrm{C}$ to allow liquefaction and analysis was performed according to WHO(1999) [9] guidelines to determine the sperm parameters include:

Sperm concentration (million/ml): Sperm concentration was calculated through the mean number of sperms in
10 randomly fields per each slide and the mean number of sperms multiply by a factor of one million $\left(10^{6}\right)$ and total sperm count was obtained by multiplying sperm concentration by semen volume.

Progressive sperm motility percent: The progressive motile sperm was counted by taking the mean number of forward progressive motile sperms.

Normal morphology percent: normal sperm morphology was reported according the following equation: Normal sperm morphology $=$ No. of normal sperm / Total sperm count X 100 .

Evaluation of chromatin maturity: in the current study used aniline blue staining method for evaluation of chromatin maturity percent of sperms. The slide was prepared by smearing $5 \mu 1$ of seminal samples. The slides were dried in air and maintained 30 minutes in glutaraldehyde (3\%) (Diluted in phosphate buffer saline (PBS)) for fixation. Slides were dehydrated then smears stained in aqueous aniline blue solution 5\% (dissolved $5 \mathrm{~g}$ of aniline blue [BDH, England] per $100 \mathrm{ml}$ of PBS) (pH 3.5) for 5 minutes. The heads of Sperms which contain immature nuclear chromatin seen as blue color, but sperms with mature nuclear chromatin did not stain and remained colorless (fig.1). The spermatozoal proportion which stained with aniline blue is measured by counting two hundred sperms in each slide by light field microscope [10].

Biochemical assay: the levels of GSH, SOD1 and CAT measured by Elabscience's assay kit and for evaluation of ROS were used Creative diagnostic's assay kit which determined by Elisa apparatus while the MDA concentration measured by modified procedure described by Guidet and Shah, 1989 [11]. 


\section{Statistical Analysis:}

Data analysis was performed by utilizing SPSS (Version 15.0). The results were expressed as mean \pm S.D. Statistical differences were determined by Least Significance Differences (LSD) test for multiple comparisons between different groups [12].

\section{Results:}

The results showed significant decrease $\quad(\mathrm{P}<0.05) \quad$ of $\quad$ sperm concentration, progressive motile sperm percent and normal sperm morphology percent in infertile men with varicocele and varicoceloctomized men compared to that of fertile men, while there were significant increase $(\mathrm{P}<0.05)$ in sperm concentration, progressive motile sperm percent and normal sperm morphology percent of varicocelectomized men compared to infertile patients with varicocele (Table 1).

The results revealed significant increase $(\mathrm{P}<0.05)$ of ROS and MDA in varicocele and Varicocelectomized men compared to fertile men, while there were significant decrease $(\mathrm{P}<0.05)$ shown in variceceloctomized men compared to varicocele patients (Table 2). Same table, also showed significant decrease $(\mathrm{P}<0.05)$ of GSH, SOD1 and CAT levels in patients complaining of varicocele and varicocelectomized men compared to fertile men, while a significant increase $(\mathrm{P}<0.05)$ were

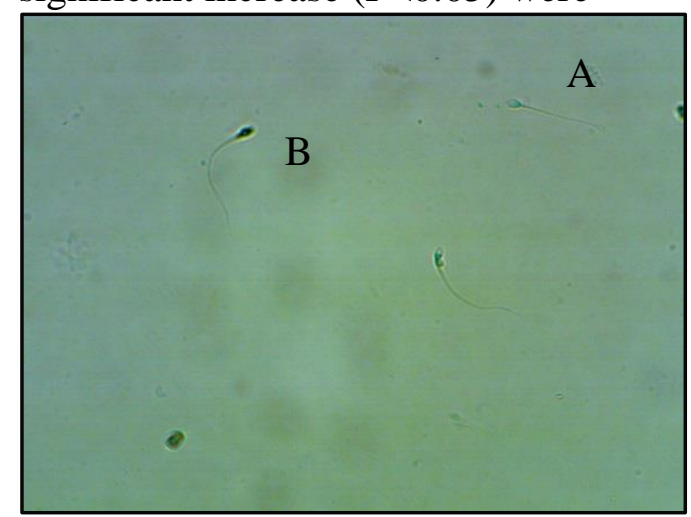

Fig. (1) Sperm Cells stained with Aniline Blue Stain. A: Sperm with unstained head (Mature Chromatin) B: Sperm with blue head (Immature Chromatin).

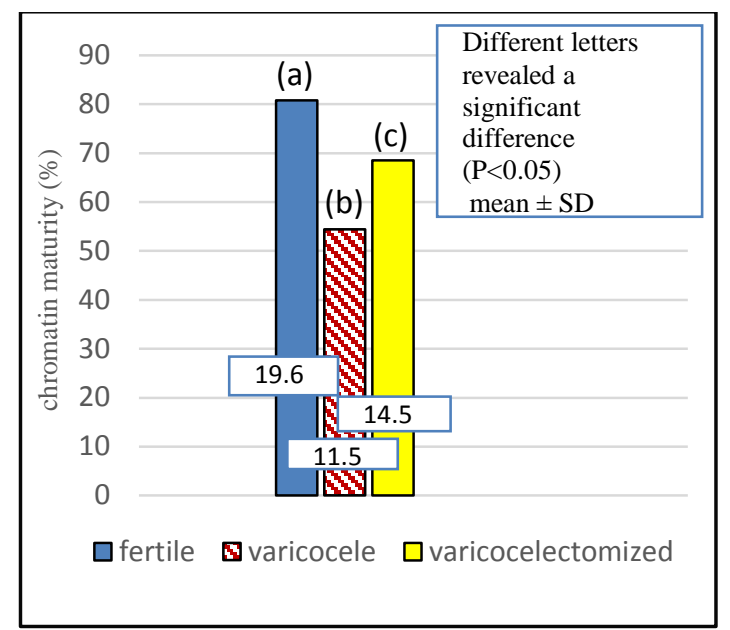

Fig. (2): Percentage of chromatin maturity in fertile $(n=25)$, varicocele $(n=78)$ and varicocelectomized men $(\mathrm{n}=76)$.

Table (1): Role of varicoceloctomy in improvement of semen parameters.

\begin{tabular}{|c|c|c|c|}
\hline Groups & $\begin{array}{c}\text { Fertile } \\
\mathbf{N}=\mathbf{2 5} \\
\text { mean } \pm \text { SD }\end{array}$ & $\begin{array}{c}\text { Varicocele } \\
\mathbf{N}=\mathbf{7 8} \\
\text { mean } \pm \text { SD }\end{array}$ & $\begin{array}{c}\text { Varicoceloctomized } \\
\mathbf{N}=\mathbf{7 6} \\
\text { mean } \pm \text { SD }\end{array}$ \\
\hline Sperm Concentration (million/ml) & $76.14 \pm 14.55(\mathrm{a})$ & $29.85 \pm 11.3$ (b) & $49.98 \pm 25.215$ (c) \\
\hline Progressive motile sperm $(\%)$ & $79.57 \pm 8.15(\mathrm{a})$ & $42.27 \pm 7.36(\mathrm{~b})$ & $49.23 \pm 21.68(\mathrm{c})$ \\
\hline Normal sperm morphology $(\%)$ & $66.42 \pm 6.33(\mathrm{a})$ & $54.34 \pm 4.45(\mathrm{~b})$ & $57.77 \pm 3.95(\mathrm{c})$ \\
\hline
\end{tabular}

Different letters denote significant differences $(\mathrm{P}<0.05)$

showed in varicocelectomized men compared to patients complaining of varicocele in the mention parameters.

The results revealed significant decrease $(\mathrm{P}<0.05)$ of chromatin maturity percent in patients complaining of varicocele and varicocelectomized men compared to fertile men, while significant increase $(\mathrm{P}<0.05)$ were shown in varicocelectomized men compared to patients complaining of varicocele in the mention parameters (fig.2). 


\section{Discussion:}

The results, of significant decrease in the sperm concentration, progressive motile sperm percent and normal sperm morphology percent of infertile patients with varicocele compared to the fertile male (control) was in agreement with Saleh et al. [13] and Erenpreiss et al. [14], whom mentioned to decreased sperm parameters in varicocele patients. As varicocele caused defects of testicular tissues includes: elevation of temperature as a results of testicular microcirculation which lead to narrowing the channels of sperm passage, or due to high level of nitric acid production, increase of toxic oxide metabolites, or by preventing the oxygen processing to sperms which may affect spermatogenesis [15]. Marmar [16] suggest that the cause of decline of sperm parameters in varicocele patients as a result of the increase in the concentration of ROS leading to increased apoptosis.

The significant increase of ROS level in seminal plasma of infertile men with varicocele was in agreement with Hendin et al. [17] whom found the levels of ROS significantly higher

Table (2): $\mathbf{R}$ of varicoceloctomy in improvement of on antioxidant and oxidant levels.

\begin{tabular}{|c|c|c|c|}
\hline $\begin{array}{ll}\text { Parameters } & \text { Groups } \\
\end{array}$ & $\begin{array}{c}\text { Fertile } \\
\mathrm{N}=25, \text { mean } \pm \mathrm{SD}\end{array}$ & $\begin{array}{c}\text { Varicocele } \\
N=78, \text { mean } \pm S D\end{array}$ & $\begin{array}{l}\text { Varicoceloctomized } \\
N=76, \text { mean } \pm S D\end{array}$ \\
\hline ROS $(\mathrm{ng} / \mathrm{ml})$ & $0.49 \pm 0.15$ (a) & $0.97 \pm 0.24(\mathrm{~b})$ & $0.64 \pm 0.17(\mathrm{c})$ \\
\hline MDA (um/l) & $4.17 \pm 1.32$ (a) & $9.5 \pm 2.17(\mathrm{~b})$ & $7.6 \pm 1.85(\mathrm{c})$ \\
\hline GSH (ug/ml) & $2.67 \pm 0.17$ (a) & $2.02 \pm 0.11(\mathrm{~b})$ & $2.5 \pm 0.07(\mathrm{c})$ \\
\hline SOD1 (pg/ml) & $314.23 \pm 20.4$ (a) & $235.25 \pm 25.3(\mathrm{~b})$ & $295.77 \pm 18.65(\mathrm{c})$ \\
\hline CAT(pg/ml) & $7.25 \pm 1.98(\mathrm{a})$ & $2.77 \pm 0.45(\mathrm{~b})$ & $5.55 \pm 1.69(\mathrm{c})$ \\
\hline
\end{tabular}

Different letters denote significant differences $(\mathrm{P}<0.05)$

in men with varicocele than in controls (without varicocele) but they did not found significant difference between fertile and infertile men with varicoceles.

The results of ROS level in varicoceloctomized men agreed with that of Mostafa et al. [18] findings after 3 months of varicocelectomy were significant decrease in ROS levels and antioxidant level was shown.

The significant increase in the concentration of MDA in infertile male with varicocele compared to fertile (control), agreed with the findings of Mostafa et al. [19], as they found significant increase in concentration of MDA in infertile males with varicocele compared to fertile males, this may be due to large quantities of the ROS that produce by immature sperms and leucocytes in patients with varicocele [20]. The significant decreased concentration of MDA in varicoceloctomized male perhaps given reason to the decrease in the number of immature sperm and leucoccyte that are responsible for the production of ROS in varicoceloctomized male [21].

The significant decreased SOD1, GSH and CAT levels in seminal plasma of infertile men complaining of varicocele was in agreement with previous study that showed significantly reduced levels of enzymatic antioxidants in the semen of infertile men with varicocele [22]. The level of GSH, SOD1 and CAT had significant increase in varicoceloctomized group compared to varicocele group which in agreement with Hosseinifar et al. [23] whom identified SOD1 significantly lower in samples before varicocelectomy compared with after surgery. These proteins are essential for normal sperm production and are affected by the heat generated by the existence of a varicocele. 
The current significant decrease in the chromatin maturity percent of patients with varicocele compared to fertile male agreed with previous [24] whom found existence of significant increase in the percentage of damaged DNA of infertile with varicocele compared to fertile male. Perhaps due to a defect in packaging of sperm chromosome and in the process of apoptosis or may be to the presence of high level of ROS which may leads to oxidative stress, thereby increasing the damage of chromatin or DNA of sperm [25].

The significant improvement in the percentage of the chromatin maturity of varicoceloctomized male compared to patients with varicocele may due to a decline in the concentration of the ROS resulting from a decrease in the concentration of leucocyte and the immature sperms [26].

It was concluded that the varicocelectomy can lead to a significant improvement in sperm parameters, the concentration of MDA, ROS, GSH, SOD1, CAT and chromatin maturity percent but does not reach to similar level that found in control group.

\section{References:}

[1]Chen, SS.; Huang, WJ.; Chang, LS.; Wei, YH. 2004. 8-hydroxy-2deoxyguanosine in leukocyte DNA of spermatic vein as a biomarker of oxidative stress in patients with varicocele. J Urol. 172: 1418-1421.

[2]Shafik, A.; Moftah, A.; Olfat, S.; MohielDin, M.; el-Sayed, A. 1990. Testicular veins: anatomy and role in varicocelogenesis and other pathologic conditions. Urology, 35(2): 175-182.

[3]Braedel, HU.; Steffens, J.; Ziegler, M.; Polsky, MS.; Platt, ML.1994. A possible ontogenic etiology for idiopathic left varicocele. J Urol. 151(1): 62-66.
[4]Werthman, P.; Wixon, R.; Kasperson, K.; Evenson, DP. 2008. Significant decrease in sperm deoxyribonucleic acid fragmentation after varicocelectomy. Fertil Steril. 90:1800-1804.

[5]Agarwal, A.; Prabakaran, S.; Sikka, S. 2006. Current Opinions on Varicocele and Oxidative Stress and its Role in Male Infertility. US Genitourinary Disease, Pp:62-68.

[6]Mostafa, T.; Anis, TH.; Ghazi, S.; ElNashar, AR.; Imam, H.; Osman, IA. 2006. Reactive oxygen species and antioxidants relationship in the internal spermatic vein blood of infertile men with varicocele. Asian J Androl. 8: 451-454.

[7]Agarwal, A.; Makker, K.; and Sharma, R. 2008. Clinical relevance of oxidative stress in male factor infertility. American Journal of Reproductive Immunology. 59: 2-11.

[8]Kim, H. and Goldstein, M. 2008. Adult Varicocele. Curr Opin Urol. 18: 608-612.

[9]WHO (World Health Organization) 1999. Laboratory Manual for the Examination of Human Semen and Semen-Cervical Mucus Interaction, 4th ed. Cambridge, Cambridge University Press UK.8-11.

[10] Hammadeh, M.; Zeginiadov, T. and Rosenbaum, P. 2001. Predictive Value of Sperm Chromatin Condensation (Aniline Blue Staining) in the Assessment of Male fertility. Arch Androl, 46: 99-104.

[11] Raad, K.; Muslih and Marwan, S. 2002. The Level of Malondialdehyde after activation with $\left(\mathrm{H}_{2} \mathrm{O}_{2}\right.$ and $\left.\mathrm{CuSO}_{4}\right)$ and inhibition by Desferoxamine and Molsidomine in the serum of patients with acute myocardial Infarction. Nat. J. of chem., 5: 139-148.

[12] AL-Rawi, K. M. 2000. Enter to Static. 2ed, College of Agriculture, Mosul University. Pp: 465. 
[13] Saleh, R.; Agarwal, A.; Sharma, R.; Nelson, D. and Thomas, A. 2002. Effect of cigarette smoking on levels of seminal oxidative stress in infertile men: a prospective study. Fertil. Steril. 78: 491-499.

[14] Erenpreiss, J.; Solveiga, H. and Janis, Z. 2002. Effect of leukocytospermia on sperm DNA integrity: A negative effect in abnormal semen samples. J. Androl. 23(5).

[15] Fazilioglu, A.; Yilmaz, I.; Mete, O.; Kurtulus, F.; Parlakkilic, O. and Guctas, O. 2008. The effect of varicocele repair on experimental varicocele induced testicular germ cell apoptosis. J Androl. 29: 29-34.

[16] Marmar, J. 2001. Varicocele and male infertility: Part II the pathophysiology of varicoceles in the light of current molecular and genetic information. Hum Reprod Up date. 7(5):461-72. Med J. 99: 44-7.

[17] Hendin, BN.; Kolettis, PN.; Sharma, RK.; Thomas, AJ.; Agarwal, A. 1999. Varicocele is associated with elevated spermatozoal reactive oxygen species production and diminished seminal plasma antioxidant capacity. J Urol. 161: 1831-1834.

[18] Mostafa, T.; Anis, T.H.; ElNashar, AR.; Imam, H. and Othman, IA. 2001. Varicocelectomy reduces reactive oxygen species levels and increases antioxidant activity of seminal plasma from infertile men with Varicocele. Int. J. Androl. 24: $261-265$.

[19] Mostafa, T.; Anis, H.; Imam, A.; El-Nashar, AR. and Osman, IA. 2009. Seminal reactive oxygen species antioxidant relationship in fertile males with and without varicocele. Andrologia. 41: 125-129.
[20] Agarwal, A.; Saleh, R. and Bedaiwy, M. 2003 Role of reactive oxygen species in the pathophysiology of human reproduction. Fertil. Steril. ; 79: 829 843.

[21] Koji, S.; Hideyasu, M. and Hiroshi, T. 2012. Pathophysiology of varicocele in male infertility in the era of assisted reproductive technology. Inter. J. of Urol. 19: 538550.

[22] Abd-Elmoaty, M.; Saleh, R.; Sharma, R.; Agarwal, A. 2010. Increased levels of oxidants and reduced antioxidants in semen of infertile men with varicocele. Fertil Steril. 94: 1531-1534.

[23] Hosseinifar, H.; Sabbaghian, M.; Nasrabadi, D. 2014. Study of the effect of varicocelectomy on sperm proteins expression in patients with varicocele and poor sperm quality by using two dimensional gel electrophoresis. J. Assist Reprod Genet. 31(6):725-729.

[24] Talebi, A.; Moein, M.; Tabibnejad, N. and Ghasemzadeh, J. 2008. Effect of varicocele on chromatin condensation and DNA integrity of ejaculated spermatozoa using cytochemical tests. Andrologia. 40: 245-251.

[25] Sharma, R.; Said, T. and Agarwal, A. 2004. Sperm DNA Damage and its clinical relevance in assessing reproductive outcome (Review). Asian J Androl. 6: 139148.

[26] Agarwal, A.; Sharma, R.; Desai, N.; Prabakaran, S.; Tavares, A. and Sabanegh, E. 2009. Role of oxidative stress in pathogenesis of varicocele and infertility. Urology. 73: 461-470. 


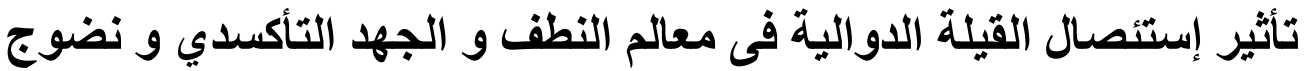

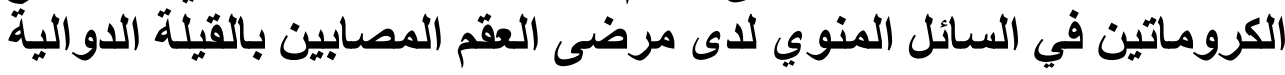

صاحب يحيى حسن **
فارس ناجي عبود*
علي جهاد ناصر

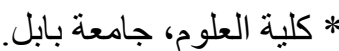

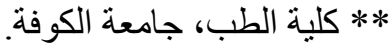

هدفت الدراسة إلى تحديد تأثير عملية استئصال القيلة الدوالية فى معالم النطف و حالة الأكسدة

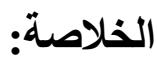

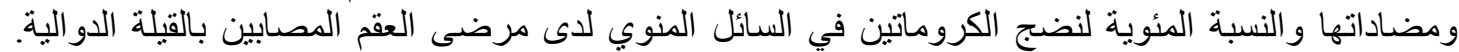

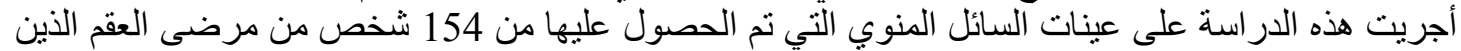

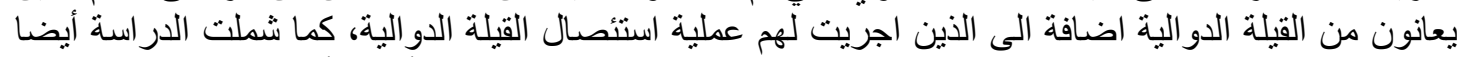

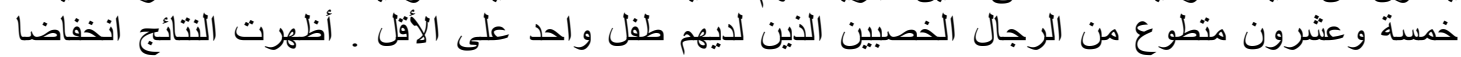

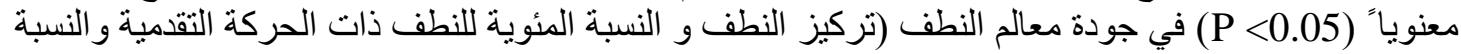

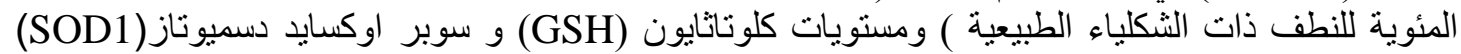

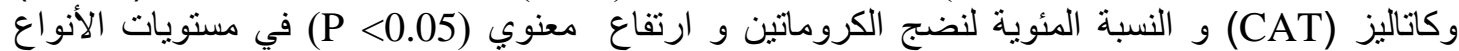

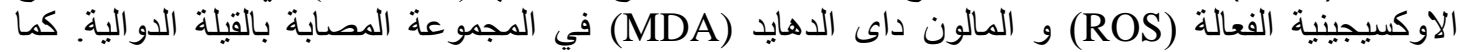

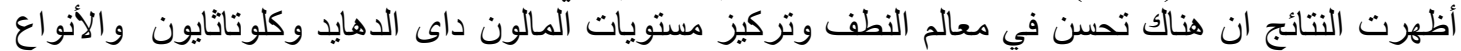

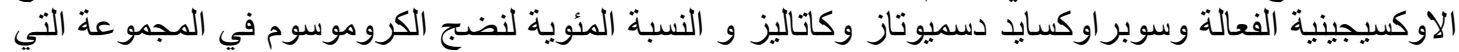

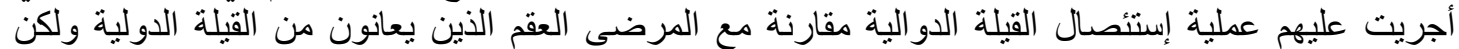

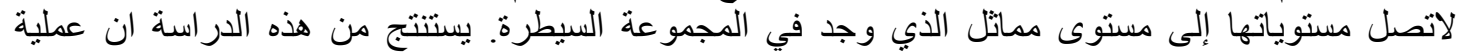

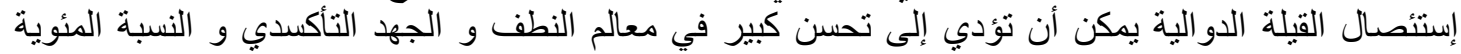

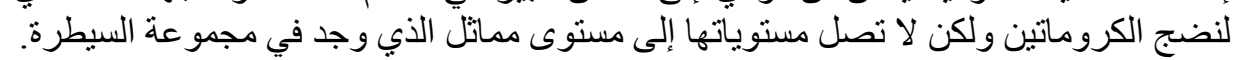
الكلمات المفتاحية: إستئصلال القيلة الدوالية، الجهد التأكسدي، النسبة المئوية لنضج الكروماتين. 